\title{
REBELIÓN SOCIAL Y CONTRAINSURGENCIA EN GUATEMALA, 1981-1983. CONFORMACIÓN ESTATAL Y POTENCIALIDAD REVOLUCIONARIA
}

\author{
Social Rebellion and Counter-insurgency in Guatemala, 1981-1983. State Conformation and Revolutionary \\ Potential
}

Sergio Guillermo Palencia-Frener

Resumen: Hacia el año 1981, el Estado de Guatemala entró en una profunda crisis. La expansión de la producción finquera y los gobiernos militares habían entrado en conflicto con la sobrevivencia misma de las comunidades indígenas del Altiplano. En este trabajo se reflexiona sobre la crisis a partir del temor estatal por la confluencia entre guerrilla y rebeldía comunitaria. Sólo así la contrainsurgencia, en tanto proceso, puede rastrearse como práctica presente en la violenta relación histórica entre comunidades y Estado. Lejos de una versión dicotómica del conflicto armado interno, veremos cómo se expresó la síntesis entre las fuerzas finqueras-estatales contra el levantamiento indígena.

Palabras clave: proceso de expropiación, mediación, conflicto interno, flujo de dominación, comunidades alzadas.

Abstract: By the year 1981 the Guatemalan State suffered a profound social crisis. The expansion of plantation production and military governments threatened the survival of indigenous communities in the highlands. In this work, we approach this crisis from the State concern about the confluence between community rebelliousness and guerrillas. In this way, we can understand the counterinsurgency plan as a process shown in the historical violent relationship between State and communities. Far away from the dichotomy of a war between guerrilla and a national army, we will see how the plantation and State forces created a counterrevolutionary synthesis against the upheaval of indigenous people.

Keywords: expropriation process, mediation, flux of domination, internal conflict, rebel communities.

Sergio Palencia Frener, maestro en sociología por el Instituto Alfonso Vélez Pliego, BUAP, México. Actualmente coordina el programa de investigación Praxis Mesoamericana Contemporánea del Instituto de Estudios Humanísticos, Universidad Rafael Landivar, Guatemala. Temas de especialización: teoría crítica y análisis del conflicto entre Estado-capital y comunidades indígenas en Mesoamérica. Correo electrónico: sergiopf83@yahoo.com.mx.

Enviado a dictamen: 04 de julio de 2013.

Aprobación: 18 de agosto de 2013.

Revisiones: 1. 
E ntre los años 1978 y 1981, el ambiente social de rebeldía era palpable en Guatemala. Desde los puños combativos de los estudiantes de nivel medio y universitario en Ciudad de Guatemala, hasta las comunidades indígenas en rebelión en áreas rurales de los departamentos de Huehuetenango, Quiché o Chimaltenango, la marea revolucionaria se veía incontenible. Asimismo, el Ejército Guerrillero de los Pobres (EGP) se asombraba de la magnitud de la rebelión indígena, la disposición a la lucha organizada y la preparación para la misma. Esta marea formaba parte del gran movimiento revolucionario que se experimentaba en la Centroamérica de finales de la década de 1970 y de inicios de 1980: una revolución sandinista que había derrocado al régimen dictatorial de Somoza, un pueblo salvadoreño que se preparaba para el asalto final a San Salvador, y miles de mozos y jornaleros indígenas en huelga con las fincas de azúcar y algodón en la Costa Sur de Guatemala (Fernández, 1988). No era casualidad que las élites guatemaltecas temieran el asalto revolucionario sobre la capital ya que, al poner en riesgo la apropiación agroexportadora de la plusvalía, basada en gran parte en la subordinación quasi-servil del indígena y otros sectores pobres, el "estado de cosas" mismo se derrumbaba. La finca, como eje articulador de la apropiación de plusvalía, era la base de las relaciones semiserviles en Guatemala. Es, pues, evidente que un levantamiento social que vinculara a las comunidades indígenas - históricamente la base de la explotación en Guatemala - con la lucha revolucionaria guerrillera pusiera en crisis las relaciones de poder del Estado y la apropiación finquera-capitalista.

Partiendo de cómo se suponía que estaban definidas las relaciones sociales de dominación desde la forma estatal finquera-anticomunista, se busca entender la contrainsurgencia desde su proceso conflictivo de constitución socio-estatal. Esto nos evita caer en el error de entender la contrainsurgencia específica de Guatemala, aquella que causó más de 200000 muertos entre 1960 y 1996, desde el canon liberal y de cumplimiento o no de acuerdos internacionales de guerra. ${ }^{1}$ En ese momento histórico surgieron en Guatemala dos extremos en conflicto derivados de la forma colonial que configuró un ordenamiento de las relaciones sociales de dominación. Por un lado, la creciente presión sobre las comunidades indígenas en tanto suplían la necesidad sistémica de movilización laboral y, por otro, el creciente proceso de expropiación de tierras en las regiones ambientalmente aptas para el café o la apropiación de tierras comunales para asegurar trabajo en las fincas. Si bien este proceso inicia hacia mediados del siglo XVIII, es hasta 1871, con la toma del poder de los liberales, cuando se establecen las pautas de expropiación territorial, mediación estatal y movilización de trabajo indígena. Así pues, los extremos en conflicto se constituyen entre la comunidad indígena y la forma de las relaciones expropiadoras/movilizadoras de trabajo, sintetizadas en la forma finquera estatal (McCreery, 1994; Tischler, 2001). De esta manera, la forma de las relaciones sociales se erige como mediación y coacción finquera sobre las comunidades indígenas, situación que crea una identidad entre grupos locales de poder - por lo general definidos estamentalmente, es decir, ladinos e indígenas de élite-y el Estado central, como regulación colectiva de dichas relaciones de dominación.

Debido al espacio y al objetivo del presente escrito, no nos es posible analizar detalladamente este proceso. No obstante, la forma finquera no fue, en ningún caso, un modelo estable, a pesar de su violencia desnuda contra las comunidades indígenas. En 1944, un movimiento urbano derrocó al régimen de Jorge Ubico, dictador que había continuado e intensificado la explotación en las fincas. Se inician los gobiernos de la llamada "primavera democrática" en Guatemala, la cual fundamentaba cambios importantes en las relaciones de gobernabilidad en el área rural, establecía nuevas mediaciones entre el Estado y la finca, e impulsaba nuevas relaciones de trabajo que irrumpieran contra la forma personal-localista de dominación finquera. En esta perspectiva promulgaba la conformación de un Estado moderno y la concreción de una relación capitalista, superando la dominación directa-servil entre finquero y mozos o jornaleros. La clave para esto era la Reforma Agraria de 1952, promulgada por el gobierno de Jacobo Árbenz. Ya antes de decretarla, miles de campesinos habían impulsado fuertes luchas contra 
finqueros locales y un movimiento de reapropiación de tierras, fuese o no con el respaldo de las instituciones agrarias creadas con el fin de la repartición. La fuerza de lucha contra la forma finquera de las relaciones sociales se había desatado, situación que puso en grave crisis al gobierno de Árbenz y fortaleció la unidad contrarrevolucionaria nacional e internacional Estados Unidos y la United Fruit Company-.

El derrocamiento de Árbenz desató, ahora con apoyo central del Estado, una cacería contrarrevolucionaria hacia todos los implicados en el régimen y, sobre todo, en la ampliación de la Reforma Agraria. Se generó un movimiento masivo de desplazamiento y se buscó reinstaurar las relaciones de dominación finquera, aunque en la realidad fuera imposible debido a los quiebres sociales y a los cambios durante la década estatal revolucionaria. El siervo de Ubico buscaba ser reinstaurado, pero no sería lo mismo. Ante la creciente crisis de legitimidad del Estado y la necesidad de asegurar la forma de dominación local finquera fundamentada en el poder central, el Estado decidió valerse de su principal recurso, el Ejército. Es así como, entre 1954 y 1963, la crisis de las relaciones sociales había abierto en los sectores dominantes la necesidad de configurar su práctica violenta de manera institucionalizada o, como diría Sandoval Alarcón, a través de la "violencia organizada". Por consiguiente, la forma estatal se estableció, en primera instancia, como contrarrevolucionaria/anticomunista para, consecuentemente, llevar dicho orden como canon social a través de la dictadura militar. Esto constituiría, en conjunto, la emergencia de una forma estatal contrainsurgente de reproducción del canon centralista finquero. Resulta fundamental entender la manera en la que actúa el Estado a través del Ejército y los finqueros, sobre todo en las rebeliones sociales entre 1978 y 1982. Una vez expuesta esta conformación estatal, aunque brevemente, relacionémosla con la manera particular como se expresó en las campañas contrainsurgentes entre 1981 y 1983. Aunque parezca invertido el análisis histórico, en este escrito veremos cómo la forma de represión de estos años da pautas para entender el desbordamiento de la forma generalizada de dominación en ese momento y años atrás.

Antes de iniciar, una aclaratoria. El presente escrito fue realizado en noviembre de 2011 como material preparatorio a la tesis del autor (2012) y presentamos aquí una versión resumida del original. En el presente trabajo analizaremos este periodo histórico, cuando se expresó, con suma radicalidad, lo que se vivió como lucha, represión o revuelta, exponiendo los momentos históricos constitutivos que muestran la contradicción entre forma y rebasamiento, de modo que irrumpió como movimiento revolucionario en apertura, por un lado, y como exterminio/reconfiguración de la violencia constitutiva de la forma estatal, por el otro. Dichos momentos históricos apuntan a la comprensión de la crisis que expresan, siendo evidente que, si están entendidos como crisis, se refieren todos al movimiento impositivo de la totalidad. En ningún instante son fragmentos inconexos y relativos, como lo supondría una interpretación posmoderna; en este sentido, siguiendo a Lukács y Adorno, la totalidad es un concepto eminentemente central para compenetrarnos en la particularidad. En tanto la crisis se compone de momentos de inflexión y posibilidad abierta, la pregunta por la revolución del ayer se expresa como tarea por la apertura de sus posibilidades hoy en día. ¿Acaso podremos aprender de la peor derrota revolucionaria del hemisferio a caminar en pos de la revolución? Tengo la certeza de que sí. Iniciemos.

\section{Flujo de dominación como forma: conformación del Estado-finca contrainsurgente}

La forma, en tanto lucha por subsumir y mediar la actividad social se concreta históricamente dependiendo de las relaciones sociales que busca imponer. Este proceso de enajenación social es, en la línea de Foucault (2006), producción de poder en el cuerpo social, tanto positiva como negativa. Esta conceptualización nos permite romper el esquema de ver el poder como posesión o toma de estructuras; más bien lo amplía en tanto que red social o actividad que conforma 
percepciones, espacios, tiempos o movimientos. Pero justamente donde Foucault pretende haber mostrado el poder como multiplicidad resistible, no superable, es donde la teoría crítica debe abrir la posibilidad de lo distinto. Esto nos refiere al rebasamiento de la forma, lo cual plantea la tensión entre actividad y ser, demandando una teoría dialéctica. Es entonces fundamental comprender la forma como "conformación histórica y sistémica de la mediación," y en el caso guatemalteco es un proceso que inicia con la identidad entre Estado y finca, el primero como ordenamiento totalizante de las relaciones sociales de dominación personalista-directo, y la segunda como concreta expropiación de plusvalía a partir del trabajo servil, etapas que posteriormente se diferencian, aunque aún de manera abierta, en tanto que explotación como paso de la subsunción formal a la subsunción real capitalista (Marx, 2001). La forma estatal, en este caso finquera, es síntesis entre mediación social y apropiación privada de plusvalía social, e impulsa una lógica específica de relaciones sociales que impugnan, a su vez, formas sistémicas de dirección y represión de actividad. La forma adquiere entonces su determinación como "movimiento que fija y fijación que mueve", articulación de una actividad enajenante que hemos llamado flujo de dominación (Palencia, 2012).

Dicho flujo está en constante lucha por imponer lógicas específicas de relaciones sociales, las cuales a su vez se expresan desde el poder como formas de subsunción y coerción. Es así como la forma es una relación social particular de poder que se expresa como momento de la totalidad del flujo de dominación. Por consiguiente, la tendencia de la forma es la subsunción y la enajenación de la actividad humana. Mas cuando la actividad social humana no reproduce el canon del poder y lo cuestiona, le pone un hasta aquí, y la forma se quiebra como relación enajenada y enajenante. La forma es respuesta, seguridad y tendencia a lo fijo, a la "estructura"; la actividad desbordante o liberadora es inseguridad y tendencia a la apertura, a lo no-definido. Es así como la actividad liberadora se constituye en un proceso de desenajenación de las relaciones sociales. Por eso, en la reflexión de la dolorosa historia de los seres humanos en Guatemala, o en general de toda la humanidad, no podemos seguir la construcción historiográfica de pasado-presente-futuro, sino la del pasado que extirpó posibilidades de lo nuevo desbordante. Sólo así no hacemos del pasado un destino -el destino de observar cómo la forma social del poder "solucionó" la crisis mediante un exterminio social y la barbarie - sino, más bien, evidenciamos el desbordamiento histórico como expurgado por el poder. Refirámonos, desde ya, a la terrible manera como la forma estatal finquera-contrainsurgente "resolvió" la crisis ante el desbordamiento de las relaciones sociales de dominación.

Una rebeldía recorría las montañas y llanos de Guatemala en 1981; lo que antes era "paisaje de la finca", hoy era erupción de los volcanes. ${ }^{2}$ El temor del Estado se había concretado y las comunidades indígenas habían confluido con la lucha armada revolucionaria. Entendida en su momento, esta confluencia no se vio en la premura de su relación como confluencia de dos historias sociales en rebeldía, sino como apoyo de las "bases a su vanguardia guerrillera.” A inicios de la década de 1980 la vanguardia guerrillera o sindical llevaría la claridad a los campesinos, fuesen o no indígenas, para la lucha organizada por la toma del poder. El ataque estatal a la rebelión hizo que esta relación entre comunidades indígenas y forma guerrillera no se profundizara, y la premura de la contraofensiva de julio-octubre de 1981 a julio de 1982 abortó la relación en proceso de maduración. Nos queda entonces la siguiente interrogante: cómo la forma estatal finquera-contrainsurgente dio el sablazo asesino al desbordamiento social. Aquí, como a continuación observaremos, salta a la vista que la forma histórica de la dominación en Guatemala se expresó como radicalización de prácticas ya usadas por el Estado y los finqueros, por ejemplo, con el castigo y el control poblacional. Acerquémonos entonces a vislumbrar cómo el flujo de dominación se expresó en la contrainsurgencia, y rescató formas finqueras y de raigambre militar de la época liberal, aunadas a la modernización sistémica contrainsurgente de las fuerzas armadas, instruidas por la catedral de la represión social en ese momento, los Estados Unidos. 
En 1966, con la intensificación de la lucha guerrillera en el oriente de Guatemala, el Estado enfrentó la amenaza con fuertes campañas de contrainsurgencia en el área. Pero, asimismo, la forma social de represión había iniciado la articulación de bandas paramilitares que, partiendo supuestamente de grupos alejados del Estado y considerados de "extrema derecha", suponían la continuidad de una forma estatal basada en conceder la violencia como prebenda a grupos acordes a su statu quo. La separación, entonces, entre Ejército como monopolio armado del Estado y bandas noestatales es ficticia; ambas presentan una continuidad y encubren un proceso que totaliza la violencia como lógica operante sobre lo particular. Anteriormente, en abril de 1932, el dictador Jorge Ubico había aprobado el Decreto 1826, el cual eximía a los terratenientes de las consecuencias de cualquier medida que tomaran para proteger sus bienes y sus tierras. Vemos cómo el Estado permitió la violencia local-finquera en 1932, así como las bandas paramilitares de sicarios en 1966, los cuales presentan, a todas luces, una continuidad evidente. Estas bandas paramilitares que se propagarían entre 1977 y 1983 fueron responsables de represión selectiva y, además, compartieron plenamente la Inteligencia militar de la época. Lo que importa destacar de estas organizaciones paramilitares es que demuestran, no un Estado débil como lo haría una visión apegada al discurso liberal, sino más bien un Estado que amplía y extiende el flujo de dominación en tanto que forma de extirpación directa de lo no-idéntico, de la rebeldía o su representación. Éste es un polo central para comprender la campaña contrainsurgente de 1981. Otra forma histórica que tiene sus orígenes en la reforma liberal es la configuración estatal de la movilización laboral, específicamente con el Decreto 177 o Ley de Trabajo Agrícola, de 1877, el cual sistematizaba la obligación de las comunidades indígenas de trabajar en el "desarrollo nacional y el progreso de la agricultura”, es decir, en las fincas (McCreery, 1994: 188). Esta movilización estaría organizada de manera estrictamente militar, a la vez que la dirección y movilización del trabajo estaría a cargo de los municipios, en ese momento liderados por ladinos liberales y afines a las fincas (Piel, 1995: 25-28).
Ahora bien, ¿cómo se relaciona el aval del Estado a las bandas paramilitares entre 1966 y 1983 con, como lo acabamos de ver, la movilización forzada de trabajadores indígenas en todo el país? Sólo penetrando la lógica de las relaciones sociales específicas como reconfiguración de la forma estatal es posible vincular estas formas de dominación. Primero, las bandas locales de orden - fueran las milicias ladinas de Chiantla en 1890, los guardias y caporales de fincas, las bandas anticomunistas después de 1954 o los policías judiciales en 1978-, así como la movilización laboral indígena -fuese bajo el Reglamento de Jornaleros de 1877, la Ley de Zapadores de 1893 o, como veremos después, las Patrullas de Autodefensa Civil en 1981—, son parte del flujo de dominación que penetra lo local como extensión de la forma central finquera. Al ser la forma finquera una organización basada en la coacción dinámica de la actividad social y en el poder directo para movilizar y obligar a trabajar en la agroexportación, esa fuerza coactiva se expresa en una lógica de fuerzas armadas que tiene por orden institucional el control, la movilización y la represión quasi-estamental de las comunidades indígenas. ${ }^{3}$ Eso que desde un análisis político se define como militarización de la sociedad y que, cabe resaltar, si bien permite analizar la sociedad como conjunto, no penetra en el proceso de expropiación de plusvalía. En este escrito se entiende ese proceso de violencia local autorizada y movilización laboral como flujo de dominación, flujo que presenta su momento estatal y finquero, o bien en general, estatal y capitalista, como movimiento integral del continuum del poder. Para el caso de la forma finquera, su relación contradictoria con las comunidades indígenas se basa en dos expresiones en lo que concierne a la concreción de su poder. Por un lado, en un inicio permite que pervivan las comunidades indígenas como fuerza de trabajo movilizable estamentalmente, para luego reforzarse por elimpulso de la mediación mercantil capitalista. Por otro lado, necesita actuar sobre las comunidades indígenas en su conjunto, no insertándolas en un proceso de generalización de la relación salarial desarrollada $\mathrm{y}$, asimismo, evita construir a sus integrantes como ciudadanos nacionales, manteniéndolos aislados y 
sin oportunidad de educación, salud o comunicación, relaciones que se establecen en un Estado-nación capitalista impulsor de la mediación universal de subsunción real del trabajo.

Consecuentemente, la contradicción de la forma estatal finquera se encontraba en que necesitaba del trabajo semiservil de las comunidades indígenas, a la vez que las mediaba externamente, no hegemónicamente en términos de Gramsci (1999: 52). ${ }^{4}$ Indígenas "para adentro", media vez sea para la apropiación de plusvalía en el trabajo servil, e indígenas "para afuera" en lo que respecta a una relación salarial que rompiera el carácter directo-coercitivo de las relaciones quasi-estamentales, dejando de lado el esfuerzo por su ciudadanización. Ésta es la forma estatal en Guatemala, heredada en gran medida de la Colonia, aquella donde las comunidades indígenas son mano de obra movilizable y estamento inferior conquistado, ahora sin siquiera poseer la prerrogativa de ser vasallos de un rey, sino mozos de una finca nacional a partir de 1871. De esta manera, vemos que la forma comunitaria entra en contradicción con la forma estatal finquera, pero ambos extremos están mediados por el flujo de dominación, de tal manera que la forma comunitaria indígena propugnada durante la Colonia y coaccionada por el régimen liberal de 1871 es, ante todo, una forma de dominación articulada con el poder estatal. Contrario al debate andino, que concebía las formas comunitarias como contrapuestas a la forma "liberal", 5 situación que corría el riesgo de naturalizar lo comunitario indígena como puro y en lucha contra lo liberal-occidental, aquí tratamos de llevar la mediación hacia la misma constitución específica del poder en la sociedad, en este caso de Guatemala. Ya establecido como historización de la forma estatal y su contradicción fundamental como comunidad indígena y proceso expropiación/movilización del trabajo, podemos entender el continuum que representa la campaña contrainsurgente a partir de julio-octubre de 1981. Para esto nos detendremos en la formación de las Patrullas de Autodefensa Civil en el área rural de Guatemala como medida de frenar el levantamiento social y la posible revolución.
Síntesis estatal contra la comunidad alzada: contrainsurgencia y Patrullas de Autodefensa Civil

La campaña contrainsurgente a partir de juniooctubre de 1981 constituye tanto una novedad como una continuidad histórica de la forma estatal. Novedad en el sentido de que radicaliza la represión social desde una planificación meticulosa, para nada asentada en el mero azar, sino partiendo de una solución a la crisis por medio del despliegue totalizante de la violencia contra las comunidades indígenas. Continuidad histórica en tanto que las formas de coerción directa y de castigo del Estado sobre la localidad pertenecen, desde ya, a la configuración histórica de las relaciones finqueroestatales. El Ejército de 1981 es la expresión de una apropiación tecnológica y de autoconsciencia sistémica que rebasa, por mucho, la existencia liberal que le dio inicio, definida aún como institución personalista en la figura del dictador. En Guatemala, para entender la racionalización estatal es necesario conocer las transformaciones del Ejército, del paso de un eje articulador de formas directas construidas alrededor del caudillo-dictador, a la adecuación de su sentido sistémico y de impulso modernizador de las relaciones sociales. De hecho, los cambios en la forma institucional del Ejército tratan de romper con la dirección unilateral de una figura coordinante, al estilo de Somoza en Nicaragua; antes bien, se adecúan a la democracia partidista como sistema aceptado de legitimación aunque, precisamente, a través de la violencia y la coerción directa dentro de sus filas. La especificidad del Ejército de Guatemala es que se fundamenta en la forma social finquera, lógica de expropiación de plusvalía originada como movilización indígena y como resguardo del proceso de expropiación. Su cambio de la forma personalista del caudillo a la forma sistémica no sustituirá su carácter externo-coercitivo sobre las relaciones sociales semiserviles, sino que más bien las mantendrá como supuesto, precisamente porque articula un proceso de subsunción formal sobre el trabajo social. ${ }^{6}$ 
Así pues, el ejército contrainsurgente que realizó el exterminio de cientos de comunidades indígenas entre 1981 y 1983 es, pues, tanto la debacle de un Estado - que no alcanzó legitimidad hegemónica de dominación ya que no estaba en su lógica constitutiva desde 1954-, como la consecuencia lógica de verse rebasado por relaciones sociales que no correspondían a la idea de orden y dirección en su realidad constitutiva. El extremo conflicto entre comunidades indígenas y proceso de expropiación/mediación llegó a quebrarse, a entrar en crisis, precisamente porque el modelo mediado de comunidades indígenas sumisas y simples reproductoras de la forma finquera había sido rebasado. El intento estatal de evitar este rebasamiento revolucionario se dio a través de permisos a regañadientes para la colonización del Ixcán y Petén, con un ínfimo apoyo al movimiento cooperativista a pesar de su modelo institucional. Esto mismo sucedió en la expresión par excellence del Estado guatemalteco, es decir, el Ejército, el cual hacia 1976 quería presentarse como institución de integración y conducción al progreso, "civilización" de la barbarie cultural, y al desarrollo. Esto fue conocido como la Acción Cívica Militar: "Las misiones que el Ejército efectúa en el campo social, corresponden a una función que, constituida en una de las características modernas de las instituciones armadas progresistas, tiende a integrarla cada vez más en la vida del país, en todas sus instancias." " La Acción Cívica Militar, para el caso específico de Guatemala, formó parte de un intento por establecer vínculos institucionales desde un contexto de crisis que venía haciéndose cada vez más evidente. El plan de control estatal a través de la imposición unidireccional de instituciones - fuesen las escuelas, los caminos, la salubridad y sanidad, o el Instituto Nacional de Cooperativas (INACOP)en realidad respondían a la ruptura evidenciada entre la incapacidad fundacional de la forma finquera para responder a una forma de apropiación de plusvalía social rebasada por la organización comunitaria, y la ampliación de su horizonte.

La crisis se profundizó a medida que el Ejército de Guatemala seguía manteniendo su forma contrainsurgente determinando la Acción Cívica, es decir, destruyendo todo rebasamiento de las relaciones que supuestamente quería propulsar. Un hecho fundamental que refleja esto es el incendio de escuelas, cooperativas y hospitales en el Ixcán hacia abril de 1981 (Falla, 2007), algunas recién inauguradas por la Acción Cívica Militar. Es aquí donde las contradicciones de la forma estatal se hacen más evidentes, ante el colapso de este último intento por mediar el control poblacional. Lo que quedó no fue más que la cara desnuda del sistema: la violencia totalizante fundadora. En diversos estudios (REMHI, 1998; CEH, 1999) se ha tendido a reproducir el argumento de que el Ejército realizó la campaña de masacres en Chimaltenango, Quiché, Huehuetenango y Baja Verapaz para quitarle el agua al pez, es decir, para separar a la guerrilla de sus bases de apoyo. Esta concepción, a nuestro entender, se queda solamente en la superficie; no comprende el desbordamiento social que se vivía en las comunidades indígenas, sino que más bien pone el énfasis en la unilateralidad de considerar que sólo la guerrilla era la amenaza real a la forma estatal. Al contrario, si partimos del quiebre de la forma estatal y, por consiguiente, de sus relaciones sociales de dominación, entonces el desafío más profundo era cómo se iba a parar la rebelión generalizada de cientos de comunidades indígenas ya no subordinadas, lo que podría dar como resultado el apoyo a la guerrilla, en este caso al EGP. Esta conceptualización rompe con la interpretación que se ha hecho del estallido revolucionario: el énfasis no está en la separación entre la guerrilla y la comunidad indígena alzada, sino en que las relaciones sociales de insubordinación desde la comunidad indígena estaban poniendo en jaque la forma de apropiación de plusvalía social basada en la finca. Esto se refleja en que el ataque de exterminio fue contra las comunidades indígenas consideradas en rebelión, como expresiones de flores que anuncian la floración generalizada, siendo la flor considerada cizaña y la floración la insubordinación generalizada revolucionaria.

Existen dos aluviones de violencia que buscaron detener la floración. La primera es la campaña contrainsurgente que tiene como objetivo destruir, eliminar o exterminar, parcial o totalmente, las 
comunidades indígenas temidas por alzadas. Este proceso se había anunciado en la serie de desbordamientos de comunidades insubordinadas ante la represión y la expropiación de sus tierras ya desde la década de 1970, si bien no se concebía al grado y magnitud que llegaría posteriormente. Ya en mayo de 1981 se daba la primera masacre en San Mateo Ixtatán, Huehuetenango, con 55 indígenas chujes asesinados. En septiembre del mismo año, el Ejército masacraba a 205 indígenas achíes en Rabinal, Baja Verapaz. Durante el año 1982 se intensificaría dicho proceso con la consolidación del plan de exterminio total o parcial de comunidades en Huehuetenango, Quiché y Baja Verapaz. Así, citemos algunas de estas atrocidades del Estado: en febrero de 1982 se mataba a 132 indígenas ixiles en Chisis, Cotzal; en marzo se asesinaba a 177 indígenas achíes en Río Negro; en marzo morían masacradas 350 personas ladinas e indígenas en Cuarto Pueblo, Ixcán; en marzo de 1982 en Estrella, Chajul, mataban a 96 indígenas ixiles; en julio morían asesinados cruelmente 373 indígenas chujes en San Francisco, Nentón. Este proceso ha sido la más violenta expresión de exterminio que ha sufrido el continente americano en el siglo XX. Las masacres fueron ejecutadas con tremenda crueldad. Se realizaron actos de humillación y barbarie antes de quitar la vida, se profanaron lugares sagrados para los pueblos indígenas — cerros, iglesias-, se golpeó la virilidad de los hombres y se violó a las mujeres; verdaderos actos de horror que buscaban ejemplificar y castigar a través de la degradación y la burla de las personas torturadas, asesinadas, violadas y castigadas públicamente.

El exterminio total o parcial de las comunidades esperaba ser ejemplificante, tanto para la misma comunidad que sufría las vejaciones y asesinatos como para las comunidades aledañas. Una vez ejecutada la violencia desnuda y habiéndose mostrado quién detentaba el poder sobre las comunidades indígenas, el Ejército procedió a romper las condiciones que habían hecho posible el rebasamiento social de la forma finquera y, por lo tanto, su crisis. Para esto, en cada campaña de contrainsurgencia buscaba primero mostrar su poder de matar como ejemplificación y lo ilimitado de su decisión sobre el cuerpo social comunitario. Ahora debía impulsar una "socialidad contrainsurgente" ahí donde todavía residía la posibilidad de que se articulara la comunización rebelde en los caseríos, aldeas o pueblos. Dicha socialidad contrainsurgente fomentaría el flujo de dominación como expresión social de control interno, siempre asumido como violencia coercitiva, pero penetrando con suma radicalidad en tanto red de poder basada en el miedo, la desconfianza, la enemistad o la sobrevivencia individual o nuclear, desgarrando así todo posible sueño compartido y transformándolo en pesadilla social llevada a cuestas individualmente. En este sentido, se socializa la represión y se individualiza el dolor. La cuestión era romper a la común-unidad en ampliación de actividad liberadora, rebelde a la reducción formal. Un ejemplo paradigmático de esta situación lo constituye la aldea Cucabaj, en Santa Cruz del Quiché:

Ante el avance de los soldados, unos pobladores lograron huir; otros, más de treinta personas, fueron encerrados en la casa del exlíder del CUC, Mateo López Calvo. Los torturaron para arrancarles información. Un declarante cuenta: "Era un símbolo que los mataran en esa casa que ese mismo día quemaron [...] iban cortando a pedazos, las orejas, las manos, la nariz, para que delataran a su propia gente, porque todos estábamos en el CUC (Comité de Unidad Campesina)" (CEH, 1999c: 132).

Las Patrullas de Autodefensa Civil (PAC) son justamente la forma elegida por el Ejército para expurgar a la comunidad indígena en rebelión, así como para enfrentar a la guerrilla. Pero, para concretar este doble cierre de socialidad revolucionaria, el Ejército impuso "la violencia para generar la violencia" contra la comunidad a partir de la misma gente, pero haciendo que cada uno de sus miembros se convirtiera en personificación del poder, posible oreja, denunciante, asesino o controlador. En muchos casos no sería solamente una cuestión de forzar a la comunidad como un todo; más bien utilizó las redes de control, de mediación y de información 
establecidas históricamente por el mismo Estado - los comisionados militares, los informantes, los grupos de poder locales, ladinos o indígenas jerarcas-. El Ejército amplió esas divisiones y las utilizó para control y represión social, instaurando autoridad a través de dichas personificaciones estatales que rompían la socialidad comunitaria rebelde. Así, también sucedió que las Patrullas de Autodefensa Civil se constituían como grupos particularizados de poder bajo el nombre de un represor local:

Esas personas estaban muy vinculadas al Ejército, pues regularmente eran confidenciales o comisionados militares que posteriormente fueron jefes de patrullas. En algunos municipios, esos grupos tomaron su denominación de los nombres o apellidos de los líderes, como por ejemplo los Zapones o los Arones, que operaban en los municipios de Santa Cruz y Uspantán, en el departamento de Quiché (CEH, 1999a: 183).

De esta manera, el Ejército insertaba el flujo de dominación como "ruptura impuesta" y asesina de la comunidad, creando desconfianza, horror y miedo a la participación social no autorizada. Asimismo, actualizaba redes de poder a partir de divisiones históricas. La división de la comunidad la realizaba mediante ritos de fraccionamiento y de conflicto, eliminando las posibilidades de que el individuo actuara en pos de la comunidad y reduciéndolo al límite del principio de conservación frente al otro. La contrainsurgencia así entendida era hacer del otro un enemigo, un potencial asesino o controlador, una amenaza a la propia existencia. Esto se confirma con la dura experiencia de la aldea de Cucabaj, lugar donde el Ejército llevó a los individuos a debatirse entre la muerte por defender la comunidad, o bien les condujo a una vida mutilada por el poder y transformada en recuerdo de traición, asesinato o tortura de los propios vecinos, familiares o comunitarios. En octubre de 1982, un teniente del Ejército capturó a un guerrillero de la región, a quien llevó encapuchado a la aldea Cucabaj para que denunciara a otros participantes:
El encapuchado indicó que no habían llegado los guerrilleros. Sin embargo, por la insistencia y las amenazas del oficial, señaló a Diego Nato, un patrullero joven, y éste señaló entonces a Santos López Tipaz, también patrullero. "Sólo yo soy guerrillero, yo no voy a entregar a ninguno, si me matan me matan a mí pero a balazos, no quiero que me amarren y me torturen" —exclamó Santos López-y, en un intento desesperado por escapar, salió corriendo. Fue acribillado a tiros por el teniente. Acto seguido, comenzaron a torturar a Diego Nato. Un declarante que se encontraba presente detalla: "Estaba en el piso, le golpearon, le patearon, le sacaban pelos a montones". Nato dio los nombres de otros patrulleros, que fueron detenidos por el Ejército: Tomás Ventura González, Tomás López Tiño y Diego Ventura López. "Hay que sacar los que están podridos para que no se pudran los demás, si no, no van a tener paz en sus casas", reprendió el oficial (CEH, 1999c: 134).

El carácter alzado es un cáncer para el Estado, los finqueros y los empresarios; por ello, optaron por el "rebasamiento de la forma," la cual se fundamenta en la inferiorización de un grupo y la superioridad del otro y en la imposición de deberes y roles para la reproducción sistémica, para naturalizar un proceso de violencia y expropiación; todos y cada uno de estos puntos responden a una totalidad que extirpa la particularidad en apertura. La forma contrainsurgente que toma el Estado entre 1978 y 1983, pero especialmente con las campañas de exterminio de comunidades y formación de PAC es, como hemos visto, novedad en su realización y continuidad en su constitución social. La expropiación de la tierra, su conversión en centro de producción y de relaciones sociales de subordinación y la movilización del trabajo servil bajo la creencia civilizadora-estamental de los explotadores, fuesen criollos o ladinos finqueros, evidencian un proceso social que, una vez profundizada la crisis, arremetió con la cara destapada: la soberbia, la humillación, la prepotencia militar, el rito del poder asesino. Ésta es la forma constitutiva del Estado guatemalteco, como lo demuestra el asesinato de Santos López en Cucabaj, 
quien prefirió morir antes que denunciar a su comunidad. Ésta es la constitución social y no meramente la forma legal de la Constitución de la República. Sobre estos cuerpos está fundada la explotación, sobre este olvido. La totalidad se evidencia como proceso de subsunción de la actividad deseada, del trabajo servil o del trabajo asalariado, así como del proceso de represión, disciplina o extirpación de la actividad rebelde, liberadora y desbordante. La forma es, como hemos visto, imposición sistémica de la actividad humana hacia la reproducción de la totalidad, la protección a como dé lugar de la ley del valor. Pero aquí donde la historia lineal termina y da por sentada la muerte, en este cementerio, nos detenemos para preguntarnos: iqué fue lo que quiso extirpar la forma finquera del Estado?, iqué es lo que consideró tan inconcebible como para exterminarlo o asesinarlo lentamente, con tortura?, ¿cuál es su miedo constitutivo? Aquí, como quien va al camposanto a volar barriletes para hablar y escuchar, nos toca abrirnos a esta pregunta por lo fundamental de la vida negada, de la actividad cortada. Sólo así nuestro volar barriletes se convierte en posibilidad revolucionaria.

\section{Desbordamiento de la forma: comunidad indígena alzada y ampliación revolucionaria (1977-1982)}

Dicho desbordamiento de la forma, en tanto movimiento de la actividad social no-idéntica, nos plantea la pregunta de la actividad liberadora. Lo oportuno del concepto de forma es que permite rebasarlo y no meramente constatarlo como fáctico; así pues, si la forma enajena e invierte la actividad humana, no puede existir una definición absoluta de las relaciones sociales y de la actividad en general que irrumpen como transformadoras. Lo único que se puede decir es que, desde su carácter histórico, la actividad social que rebasa la forma es actividad desenajenante, proceso de pregunta, inquietud, éxodo, apertura, responsabilidad y autoconsciencia de la contradicción. Así planteado, el rebasamiento de la forma no puede sujetarse a seguridades prefiguradas, no hay categorías de estasis que le den solidez a su caminar, más bien su paso es la experiencia de un todavía-no (Bloch, 2007) en la profundización de la crisis. Dicha crisis es la evidencia de la contradicción enfrentada, por lo que el rebasamiento de la forma se nos presenta más bien como un proceso de parto y nacimiento: "En el momento de dar a luz, la mujer se aflige porque le llega la hora del dolor. Pero, después que ha nacido la criatura, se olvida de las angustias por su alegría tan grande: ien el mundo ha nacido un hombre!" (Juan, 16, 21). El momento del nacimiento social de la actividad desenajenante es único, irrepetible; la propia experiencia de llevar la vida a pesar de la muerte social hace que el alumbramiento no pueda ser extirpable, pues ha sentido sus propios pasos y ha abrazado un instante de unión. Ésa es la rabia del poder, de la forma; la actividad desenajenante como rebasamiento le ha mostrado lo inocuo de sus fines y lo estrecho de miras de su horizonte de tradición o progreso. Así, todo rebasamiento busca expurgar exterminando su impulso, su luz, a través de la cárcel, la reglamentación, el golpe de advertencia, la tortura, el lento sufrimiento, el asesinato o la masacre. La forma busca llamarse estructura y encerrar lo que la constituye, precisamente en la violencia que convierte al ser humano en un medio para su reproducción. Por el contrario, lo vivo tiende a la amplitud y la apertura. $\mathrm{O}$, como diría de manera realmente hermosa William Blake en los Proverbios del infierno: "la cisterna contiene, el manantial desborda."

Así pues, para repensar el cambio social radical es necesario dejar de adoptar la forma del pensamiento sistémico, aquel que establece lo dado como lo definitivo, aquel que se identifica con los últimos hechos por su pretendida "objetividad" y constatación de lo evidente y manifiesto. En lugar de partir de lo último, es decir, de la barbarie de la contrainsurgencia y de la derrota histórica del movimiento revolucionario, la mirada revolucionaria deberá conocerlos y sufrirlos; el dolor de lo extirpado no-idéntico es nuestro dolor, pero no para morir en él, sino para resucitarnos en su fuerza. A partir del exterminio social sufrido en Guatemala, la ciencia social puede quedarse en lo acontecido como configuración última, pero para la teoría crítica el pasado sigue desbordando, sigue siendo manantial, voz que espera escucharse y entenderse de manera distinta 
y más profunda en nuestro camino. Por lo tanto, el conocimiento de las causas y configuraciones de las relaciones sociales que llevaron al exterminio y muerte de las comunidades es imprescindible, pero como momento de la pregunta por nuestra historia o, mejor dicho, por nuestro quiebre de la historia. La pregunta ahora se puede también plantear de la siguiente manera: ¿qué fue lo que desbordó la forma en la especificidad estatal de Guatemala entre 1978 y 1982? Constatemos entonces el desbordamiento a partir de lo que negó la forma social del poder con la contrainsurgencia.

Como mostramos anteriormente, la forma estatal finquera tuvo su origen como síntesis de un proceso que venía desde las contradicciones del siglo XVIII. La finca, a partir de su estatalización y violencia constitutiva de relaciones sociales, es una forma que lleva implícito el impulso capitalista como exportador de mercancía agrícola desde la movilización estamental del trabajo. He ahí su núcleo siempre en tensión, contradictorio, incluso para sus personificaciones. La revolución liberal llevó el impulso capitalista -el impulso de la cosa idolatrada - hacia la violencia finquera de la expropiación continua y hacia el deseo de asegurar trabajadores permanentes o estacionales, tomándolos o vomitándolos del centro productivo dependiendo de sus necesidades del momento. Pero, al contrario de las posibilidades de apropiación en el capitalismo industrial, la forma finquera tiene dos límites, el primero es el ciclo de siembra, cuidado y crecimiento de la mercancía agrícola; el segundo el de la necesidad de mano de obra para recolectar, tapiscar o transportar - en el caso del café-. Cada mercancía agrícola admite posibilidades de sustitución tecnificada de mano de obra dependiendo de la calidad y cantidad pretendida de exportación. Ahora bien, recordemos que el hábito del cálculo y el aprovechamiento del capital en el desembolso requiere del desarrollo de una racionalidad en las relaciones sociales que no estaba presente en los iniciadores de la revolución liberal, sino sólo en sus nuevos socios, los capitalistas finqueros alemanes de la Verapaz durante la época. El hábito estamental del finquero guatemalteco se apoyó en la movilización coercitiva del trabajo de las comunidades indígenas, como señores de horca y cuchillo, situación que terminaron reproduciendo los capitalistas alemanes devenidos finqueros a partir de la lógica de relaciones de subordinación local. Dicho hábito finquero llevaba adherido a su pensamiento y práctica cuatro siglos de inferiorización del indio conquistado y consideraba su trabajo como un derecho estamental, ahora legalizado por el Estado. El finquero naturaliza la tierra apropiada y el trabajo que levanta la cosecha como un derecho estamental, mientras que se humaniza en el gozo de la prebenda y, sobre todo, en la violencia que ejerce para afirmar su mundo.

El mundo del finquero tiene como fecha de instauración el triunfo liberal de 1871, año que se ha interpretado como la llegada de los ladinos al poder, como la creación del estado moderno a partir del ataque contra las instituciones coloniales que defendían, en tanto vasallo, al indio. De ahí que el conflicto entre estamentos criollos y ladinos no fuese el de un nuevo estado que se impone a otro, sino el de la profundización del flujo de dominación colonial en la ampliación de la disposición sobre los indios. En este caso, los indios dejan de ser vasallos conquistados, se les elimina las prebendas de vasallos y se les deja en la desnuda relación de dominación. Los estamentos se hacen Estado y adquieren su poder. Todo parecería entonces insinuar que los ladinos toman el poder, lo cual es cierto en tanto que flujo de dominación que se personifica en la ampliación estatal de un estamento racista, pero es falso en tanto que, precisamente por ser personificación del poder, momento de la dominación, no todo el estamento ladino es expropiador y movilizador de trabajo. Este matiz entre el ladino como personificación de la expropiación de tierra y de la movilización laboral del indio y, por otra parte, del estamento ladino que no personifica necesariamente dicha relación social, es el que hace que el énfasis no sea el ser ladino, sino la actividad de dominación posible en el estamento ladino. Prueba de esto es el lado normalmente pasado por alto: el papel de ciertos sectores indígenas en la reconfiguración del flujo de dominación en las comunidades indígenas. El Estado liberal como forma lleva implícito un movimiento de personificación que no derrumba lo 
estamental, sino que lo impone y estimula como poder de dominación. Los indígenas que conformaban una élite de origen colonial no son orillados en este proceso, sino que se mueven en la tensión entre la relación con la forma estatal expropiadora y movilizadora a través de los estamentos, y la comunidad indígena a la cual pertenecían y que se veía golpeada por la violencia sistémica. Por eso es imprescindible matizar el doble movimiento que expone la transformación impuesta por la forma estatal a partir de 1871: por un lado le imprime a la división estamental el carácter totalizante de la dominación estatal, imbricada en las necesidades locales para la inserción en el mercado capitalista; por otro lado, al totalizar lo estamental en la forma estatal, logra universalizar la dominación y, precisamente por esto, deja sentadas las bases para un posible y paulatino movimiento que supere lo estamental y generalice una dominación abstracta de mediación capitalista.

Por consiguiente, iqué pasa con una forma estatal basada precisamente en la contradicción entre dominación estamental y universalización de sus relaciones de poder a toda la sociedad? $\mathrm{Si}$, como dijimos al inicio, la tensión más fuerte se da entre comunidad indígena y mediación estatal estamentalizada, el gran temor del segundo extremo es el levantamiento generalizado de la comunidad indígena frente al sistema que se basa en su dominación. Esto significa, ni más ni menos, el rebasamiento de la misma comunidad en su forma colonial y de mediación liberal, y el desatamiento de las contradicciones en su seno, justamente contra las formas comunitarias de imposición personificadas muchas veces en alcaldes ladinos o indígenas, así como en principales o habilitadores mediadores de la forma finquera. El movimiento emancipatorio de las comunidades indígenas irrumpe como dos momentos complementarios aunque no idénticos, siendo uno la paulatina ocupación, como lucha, de los sectores estamentalizados y ocupados por ladinos, por constituir ellos el estamento estatal del "progreso" y "nacional". El segundo movimiento está dividido sólo analíticamente, pero en constante conflicto, como movimiento de apertura contra las nuevas mediaciones estatales, es decir, como ampliación de la socialidad comunitaria rebelde. Detengámonos brevemente en el primer movimiento.

Aquí vemos todas las riñas por el control del poder municipal tras la embestida que imprime la forma estatal a partir de 1871. Dichos espacios municipales eran imposición estamental del Estado, por lo que la lucha por ellos era en ese contexto una afirmación de lo negado. El mismo movimiento sucede con la lucha de los indígenas por los espacios y actividades comerciales, los cuales le habían sido prácticamente negados al serles impuesta su condición de fuerza de trabajo para las fincas. Las luchas por el poder municipal se inician a principios del siglo XX y comienzan a hacerse fuertes entre 1920 y 1940. Se trató de un movimiento por ocupar los lugares estamentalizados negados que se producen también en las luchas por desarrollar actividades no subsumidas al canon del mozo finquero. Tanto la lucha por el poder municipal como por el comercio van de la mano. Esto fue impulsado entre 1910 y 1930, lo cual se aprecia en los documentos históricos de exención de trabajo en las fincas o en los batallones de zapadores bajo la Ley contra la Vagancia ubiquista de 1934. El estallido ya había iniciado hacia 1920, pero se generaliza cuando la forma estatal estamentalizada-finquera entra en profunda crisis y el levantamiento capitalino del 20 de octubre de 1944 profundiza la misma hacia las relaciones sociales en el área rural, sobre todo en lo que respecta al Código de Trabajo, las leyes municipales y de representatividad, las mediaciones de las grandes organizaciones sindicalescampesinas y, por supuesto, el centro de ataque contra la forma personalista del estado estamentalizado, la Reforma Agraria arbencista. En ese momento convergen las luchas sociales contra la forma estatal basada en la apropiación oligárquica de plusvalía, así como contra la dominación estamental y personalista, lo cual se puede encontrar en la búsqueda de amplios sectores capitalinos, como la lucha de ciertos sectores indígenas por ocupar los puestos administrativos municipales, asî como por la ampliación del comercio.

El centro neurálgico que atacaba la forma estatal conformada a partir de 1871 es, como ya lo hemos dicho, la expropiación de la tierra como proceso y, una vez consolidado este movimiento, la apropiación de la 
plusvalía agroexportadora a través de la movilización laboral de las comunidades indígenas. La emancipación ciudadana del indígena se concretaría en la nueva mediación de una forma estatal impersonal y capitalista, por lo menos como horizonte, postulada a través de las acciones de impulso estatal, como la Reforma Agraria y la reglamentación mercantil de la fuerza de trabajo. Este proceso se ve truncado por la intervención de la totalidad capitalista llevada en su momento por Estados Unidos en su lucha contra el "comunismo", así como por la lucha de los sectores oligárquicos beneficiados por la forma finquera. Mas el proceso de lucha por y contra los espacios estatales estamentalizados no podía detenerse; el impulso era mayor, si bien ahora, con la contrarrevolución de 1954, las fuerzas que desean eliminar todo cuestionamiento del orden social buscan consolidarse. De ahí que, necesariamente según considero, una contrarrevolución en el contexto de las relaciones sociales impulsadas como lucha en la Guatemala de finales de los cincuenta sólo pudiera establecerse a través de la represión directa, de la profundización de la contrainsurgencia como movimiento del flujo de dominación, es decir, como represión generalizada contra las relaciones sociales que atentaran contra el statu quo basado en la separación ladino-indígena, campesino-obrero y, sobre todo, contra las posibilidades de convergencia entre el movimiento totalizante rebelde de la guerrilla y las comunidades indígenas en alzamiento hacia finales de la década de 1970. Desde este punto, la contrainsurgencia es lucha contra este movimiento articulado.

Por lo que respecta al segundo movimiento emancipatorio indígena que, como habíamos acotado anteriormente, si bien puede complementarse con el primero, no es idéntico a él. Hay algunos matices importantes que destacar. Nos referimos al fuerte movimiento de desborde y rebasamiento de la forma comunitaria que articulaba el flujo de dominación. ${ }^{8}$ Aquí las mediaciones estatales y comerciales del primer movimiento se ven rebasadas por una lucha más profunda, transformadora, donde, justamente, el cuestionamiento y la lucha se dieron contra las bases mismas de la dominación estatal finquera de la expropiación de la tierra y la movilización laboral de la comunidad. Surgen como un verdadero huracán luchas poderosas de las comunidades contra la expropiación de la tierra, contra las personificaciones sociales de la forma finquera en la localidad. Desde luego, esta lucha dentro del marco de la reconfiguración del flujo de dominación de la forma estatal finquera llevaba consigo una negación a reproducir los cánones que habían obligado a las comunidades indígenas a trabajar en las fincas de la costa sur. El modelo articulador entre la expropiación local y el trabajo en las fincas habría de ser cuestionado profundamente, por lo que, desde el abismo de la humillación, del dolor histórico, surge en abierto desafío el carácter de lo comunitario en rebeldía, el alzamiento de la socialidad negada de las comunidades indígenas. La autodeterminación de estas comunidades pone en crisis la reproducción de la totalidad de las relaciones de dominación.

Para el Estado, que había temido un levantamiento a gran escala con lo que sucedió en San Juan Ixcoy en 1894 y en Patzicía en 1944, es decir, una rebelión "india" contra los ladinos y extranjeros, el terror se lo figuraba estamentalmente a través de lo que había significado a lo largo de la historia la expropiación ladina, criolla y extranjera. De ahí que usualmente se temiera una guerra de castas como la de Yucatán en el siglo XIX donde los indios se enfrentaran a los ladinos. Pero este imaginario del siglo XIX ya no sintetizaba la lógica de las relaciones sociales de dominación en la segunda mitad del siglo XX. Primero, la forma estatal que se había impuesto a partir del movimiento contrarrevolucionario ya no reproducía los regímenes personalistas del caudillo, del dictador. Ahora la forma estatal se configuraba en torno a una aprehensión sistémica de las relaciones sociales, donde lo nacional se definiría como anticomunista y la institucionalidad estatal demarcaría todo descontento hacia la propiedad de la tierra y la movilización laboral como germen del comunismo, es decir, como amenaza estatal. El comunismo se transformaría en una cruzada mundial contra los "valores" de la democracia y la igualdad, así como en un atentado contra las formas opresivas tradicionales del catolicismo conservador - cachureco- guatemalteco, central en la cultura que 
había llevado al Cristo de Esquipulas en las marchas anticomunistas. Luego, pues, el comunismo se demoniza como movimiento que desvía a las bases de la forma estatal, de la institucionalidad y de la moralidad nacional.

¿De qué magnitud sería el horror de las formas estatales y sus personificaciones ante la posibilidad de que los "indios", el estamento base de la explotación, se hicieran comunistas? La idea de un "indio comunista" era la confluencia de dos cruzadas que ponían en peligro potencial las bases del Estado y la reproducción de las relaciones sociales de dominación. Este indio comunista al que tanto temían las élites guatemaltecas era demonizado por su insubordinación como estamento oprimido y como parte de un movimiento "extranjero" en el interior. Ya en tiempos de Ubico, a raíz del temor que inspiró la rebelión de 1932 en El Salvador, se hablaba de bolchevismo rural. Dos demonios, indio y comunista, que se conjugan siempre con lo que podría poner en peligro el modelo de apropiación de plusvalía heredado del régimen liberalfinquero. Dos demonios, comunista e indio, que se mostrarían como externos a la identidad estatal y, por lo tanto, extirpables. Este doble demonio temido se concretaría, según sus temores, cuando en realidad las comunidades indígenas se movieran más allá del marco de dominación histórico, cuestionándolo, luchando por las tierras robadas, demandando mejores condiciones sociales de trabajo o, más profundo aún, negándose a trabajar en las fincas y a construir su vida en la propia localidad. Luchar contra la expropiación, invadir tierras, cultivarlas, cooperar en la producción social y dejar paulatinamente los marcos de movilización laboral de las habilitaciones era, en el fondo, un ataque frontal a un Estado que se configuraba en torno al dominio local como totalización personalista de las relaciones de dominación. Cuando la ola inmensa de la socialidad comunitaria en rebeldía comienza a darse en todo el país, fuese en las luchas de las comunidades de Panzós contra el finquero expropiador, fuese en las acciones de sabotaje y lucha de los indígenas q'anjobales de San Miguel Acatán contra la compañía Cuchumaderas, fuese en la resistencia de las comunidades kaqchikeles de Parramos y San Martín Jilotepeque a desalojar las tierras, pues ya no podían pagar los intereses de los préstamos bancarios. Ahí, en ese preciso instante, la forma estatal percibió el proceso incontenible de levantamiento social, aunado a una guerrilla que parecía fortalecerse más desde el norte del Quiché. La rebelión estaba en marcha como desbordamiento de las categorías del poder, como estallido de las formas de movilización laboral y expropiación, alguien surgía de la nada ahí donde la forma niega constitutivamente lo no-idéntico.

Éste fue el desbordamiento que puso a temblar al Estado y a los finqueros en Guatemala, el mismo que obligó a una masiva huida de capitales a Miami en 1980 y expandió la crisis de la forma agroexportadora a nivel nacional. Esto es lo que pasa por alto el antropólogo estadounidense David Stoll con su idea generalizadora de que los indígenas estuvieron "entre dos fuegos" (Palencia, 2011). Así también, lo que el sociólogo francés Yvon Le Bot entendió de manera tan reducida como movimiento indio local que no necesariamente entraba en contradicción con el Estado, siendo el origen del exterminio la amenaza guerrillera tomada unilateralmente (Le Bot, 1993: 301). Si bien la masacre de indígenas en San Juan Ixcoy y Patzicía no explica la complejidad histórica de la contrainsurgencia de 1981-1982, sí genera relaciones del tipo de actitudes de la forma estatal y local de la violencia contra el más mínimo intento de levantamiento indígena en Guatemala. Es por eso que repensar la contrainsurgencia es una tarea inmediata y necesaria para construir los nuevos caminos del cambio social radical. La socialidad rebelde y potencialmente desenajenante deberá tomar otros caminos, reflexionar los puntos de inflexión y combatividad, pero sobre todo generar condiciones y reflexión para radicalizar las expectativas, dejar de beber el agua rancia de la cisterna de la forma estatal y capitalista, apuntar alto y profundo de nuevo. El reto de la revolución hoy es penetrar el hielo de las formas y discernir cómo el flujo de dominación oprime en tanto movimiento de la totalidad, ahí donde el capital lucha por reducir la actividad social a mero trabajo productor de plusvalor. La creación de una socialidad comunitaria, 
de nuevos lazos de unión y de disposición de escucha, como tejidos, podrá abrir las posibilidades de la memoria revolucionaria y expandir las luchas en pos del desbordamiento. La creatividad como compromiso y el compromiso de la creatividad son bastiones que se impulsan desde los deseos radicales de cambiar la sociedad. Desbordar la forma es apertura revolucionaria del mundo hacia lo nuevo, con un corazón que une lo que el tiempo había separado.

\section{Notas}

${ }^{1}$ Para una postura que contrasta las masacres del Ejército en el norte del departamento de Quiché desde una perspectiva jurídico-liberal, véase el libro de Roddy Brett (2007). Esto sucede cuando un estudio, en su afán de denuncia jurídica de la violencia contrainsurgente, termina preocupándose más por los crímenes desde un análisis de violación del derecho internacional y, precisamente por esto, no penetra en la especificidad de las relaciones sociales constitutivas.

${ }^{2}$ En su libro La patria del criollo, Severo Martínez Peláez analiza cómo los dominantes, en este caso Fuentes y Guzmán, conciben las relaciones sociales y naturales como paisaje y heredad.

${ }^{3}$ Cabe aclarar que aquí estamos viendo la forma general de las relaciones sociales constituidas como forma estatal. Existen matices importantes que aquí no trataremos, como la potencialidad de la forma finquera de transformarse en forma capitalista de organización, es decir, de Estado moderno de mediación general y abstracta, en lugar de en forma personalista-soberana, como el régimen de Somoza y su Guardia Nacional. Esto es central para comprender el proceso de transformación del ejército en forma sistémica a partir de 1963.

${ }^{4}$ Considero que el concepto de hegemonía posibilita una comprensión de las relaciones del Estado moderno y de las mediaciones capitalista que impulsa. Sin embargo, para una teoría del quiebre de la forma, el análisis de Gramsci no resuelve, a mi entender, la compenetración conceptual con el flujo de dominación que se establece desde la apropiación social de plusvalía.
5 Véanse los estudios de Raquel Gutiérrez (2001) y de Lucía Linsalata (2009). Ambos escritos tienden a absolutizar la "forma comunitaria" como política de horizontalidad, asamblea y consulta, contraponiéndolo a la "forma liberal" del Estado que se caracterizaría por su verticalidad, representatividad y dictamen unilateral. Si bien implícitamente estos argumentos critican la política estatal y de representatividad, práctica que repite la izquierda, termina siendo un análisis que deja de lado la complejización de cómo se conforma históricamente la comunidad indígena y, precisamente, pasa por alto la reproducción de la totalidad en la particularidad comunitaria. Termina repitiendo la imagen de lo comunal como política completamente otra de lo estatal, dejando a un lado la mediación que complejiza las relaciones que se establecen como formas productoras y reproductoras de orden estatal y capitalista.

6 Esto no niega el proceso de industrialización en Guatemala entre 1954 y 1980; al contrario, explica cómo la forma estatal articulada sobre las relaciones directas-serviles, con énfasis en la explotación rural, redundó en un reducido avance de formas sociales de valor de cambio y, por ende, de impulso al proceso de subsunción real en el cual se basa la industria.

7 Ejército de Guatemala (1976), "Ejército-Comunidad", en Archivo Selser, UACM. Fondo A, F GTl, Serie Guatemala, Sección Fuerzas Armadas.

${ }^{8}$ Al afirmar que la forma comunitaria es expresión de relaciones sociales de dominación configuradas también desde la forma estatal finquera, no estamos para nada negando que existiera una socialidad comunitaria que, a través de la autonomía local, mantuviera relaciones sociales y con la naturaleza igualmente enajenadas. Al contrario, como concibo en este escrito, la emancipación desde y contra la forma comunitaria indígena-liberal es ampliación de las posibilidades de una socialidad comunitaria en expansión y apertura, abriendo las puertas hacia el cuestionamiento de relaciones de poder tradicionales, patriarcales y gerontocráticas asentadas en la forma comunitaria tradicional. En resumidas cuentas, nos referimos a la ampliación de las potencialidades de socialidad desenajenante. 


\section{Referencias bibliográficas}

Adorno, Theodor Wiesengrund (2006), Métaphysique. Concept et problèmes, París: Payot \& Rivages.

Brett, Roddy (2007), Una guerra sin batallas: del odio, la violencia y el miedo en el Ixcán y el Ixil, 1972-1983, Guatemala: F\&G.

Comisión para el Esclarecimiento Histórico (CEH) (1999a), "Las Patrullas de Autodefensa Civil", en Guatemala, memoria del silencio, Guatemala: UNOPS, t. II, pp. 181-235.

Comisión para el Esclarecimiento Histórico (CEH) (1999b), "Caso ilustrativo núm. 53. Miembros de las PAC obligados a matar a otros miembros de las PAC", en Guatemala, memoria del silencio, Guatemala: UNOPS, t. VII, pp. 163-168.

Comisión para el Esclarecimiento Histórico (CEH) (1999c), "Caso ilustrativo núm. 43. Los patrulleros de Cucabaj", en Guatemala, memoria del silencio, Guatemala: UNOPS, t. VII, Casos Ilustrativos Anexo I, pp. 131-138.

Falla, Ricardo (2007), Masacres de la selva. Ixcán, Guatemala. Guatemala: USAC.

Fernández, José Manuel (1988), El Comité de Unidad Campesina: origen y desarrollo, Guatemala/Madrid: Centro de Estudios Rurales Centroamericanos (CERCA).

Foucault, Michel (2006), Surveiller et punir. Naissance de la prison, París: Gallimard.

Gutiérrez, Raquel (2001), "Forma liberal y forma comunal de la política”, en Raúl Prada et al., Pluriverso, Teoría política boliviana, La Paz: Comuna.

Le Bot, Yvon (1993), La guerra en tierras mayas. Comunidad, violencia y modernidad en Guatemala (1970-1992), México: FCE/Sociología.

Linsalata, Lucía (2009), El ethos comunal en la política boliviana. Una reflexión acerca de las formas comunales de la política en el mundo aymara contemporáneo, (tesis inédita de maestría), UNAM, México.

Lukacs, George (2004), Histoire et conscience de classe. Essais de dialectique marxiste, París: Les Éditions du Minuit.

Martínez Peláez, Severo (2003), La patria del criollo. Ensayo de interpretación de la realidad colonial guatemalteca, México: FCE.

Marx, Karl (2001), El capital I. Crítica de la economía política. México: FCE.

McCreery, David (1994), Rural Guatemala, 1760-1940, Palo Alto, California: Stanford University Press.

Palencia Frener, Sergio Guillermo (2011), “iEntre dos fuegos? Neutralización de la lucha ixil en David Stoll y la cuestión de la memoria revolucionaria en Guatemala (1970-1983)", en Albedrío.org, mayo, pp. 1-62. 〈http://www.albedrio.org/htm/otrosdocs/ comunicados/issuus/Documentos-0012.htm> [30 de mayo de 2013].

Palencia Frener, Sergio Guillermo (2012), Conformación estatal y lucha comunitaria en Guatemala, (tesis inédita de maestría), BUAP, México.

Piel, Jean (1995), El departamento del Quiché bajo la dictadura liberal (1880-1920), Guatemala: CEMCA.

Postone, Moishe (2007), Marx Reloaded: repensar la teoría crítica del capitalismo, Madrid: Editorial Traficantes de Sueños.

Proyecto Interdiocesano Recuperación de la Memoria Histórica (REMHI) (1998), Guatemala: nunca más. El entorno histórico, Guatemala: Oficina de Derechos Humanos del Arzobispado de Guatemala, t. 3.

Stoll, David (1993), Between Two Armies in the Ixil Towns of Guatemala, Nueva York: Columbia University Press.

Tischler, Sergio (2001), Guatemala 1944: crisis y revolución, Guatemala: F\&G.

Torras, Rosa (2007), Así vivimos el yugo. La conflictiva conformación de Colotenango como municipio de mozos (18251947), Guatemala: AVANCSO. 